Regulating Traffic Safety 
This page intentionally left blank 


\section{Regulating Traffic Safety}

Martin Friedland

Michael Trebilcock

Kent Roach 
www.utppublishing.com

(C) University of Toronto Press 1990

Toronto Buffalo London

Printed in Canada

ISBN 0-8020-6764-6

(

Printed on acid-free paper

\section{Canadian Cataloguing in Publication Data}

Friedland, M. L. (Martin Lawrence), 1932-

Regulating traffic safety

Also published in: Securing compliance:

seven case studies

ISBN 0-8020-6764-6

1. Traffic safety. 2 . Traffic regulations.

I. Trebilcock, Michael J., 1941-

II. Roach, Kent, 1961-

III. Title.

HE5614.F73 $1990 \quad 363.12^{\prime} 56 \quad$ C90-093832-3 